\title{
Dentin Hypersensitivity After Treatment With Desensitizing Agents: A Randomized, Double-Blind, Split-Mouth Clinical Trial
}

\author{
Jorgiana Silva de ASSIS ${ }^{1}$ \\ Lidiany Karla Azevedo RODRIGUES ${ }^{2}$ \\ Cristiane Sá Roriz FONTELES ${ }^{3}$ \\ Regina Cláudia Ramos COLARES ${ }^{4}$ \\ André Mattos Brito de SOUZA ${ }^{1}$ \\ Sérgio Lima SANTIAGO ${ }^{2}$ \\ ${ }^{1} U F C$ - Federal University of Ceará, Fortaleza, CE, Brazil \\ ${ }^{2}$ Department of Operative Dentistry, School of Pharmacy, Dentistry and Nursing, \\ UFC - Federal University of Ceará, Fortaleza, CE, Brazil \\ ${ }^{3}$ Department of Clinical Dentistry, School of Pharmacy, Dentistry and Nursing, \\ UFC - Federal University of Ceará, Fortaleza, CE, Brazil \\ ${ }^{4}$ Science and Health Center, University of Fortaleza, Fortaleza, CE, Brazil; \\ UFC - Federal University of Ceará, Fortaleza, CE, Brazil
}

\begin{abstract}
The aim of this study was to evaluate the efficacy of two desensitizing agents in the reduction of dentin hypersensitivity in a randomized, double-blind, split-mouth clinical trial. Seventy-seven teeth from 13 patients that presented some degree of sensitivity to probing and/ or air stimulation were treated with one of the following desensitizing agents: Oxa-Gel (G1), Sensi Kill (G2) and placebo gel (G3 control). According to paired t-test, all treatments, even the placebo gel, were capable of reducing sensitivity scores for both stimuli. Analysis of data by ANOVA and Tukey's test $(\alpha=0.05)$ showed that the sensitivity scores were significantly lower only for Sensi Kill in comparison to the other products (Oxa-Gel and placebo), when air stimulus was applied. It may be concluded that treatment with Sensi Kill presented a slightly better performance in reducing dentin hypersensitivity when compared to the other desensitizing agent.
\end{abstract}

Key Words: dentin hypersensitivity, hyperesthesia, desensitizing agents.

\section{INTRODUCTION}

Dentin hypersensitivity can be defined as a temporary pain or exaggerated response from the exposed dentin to chemical, tactile, thermal or osmotic stimuli in the buccal environment, which would not normally occur in a healthy tooth (1). Under normal conditions, dentin is covered by enamel or cement and does not suffer direct stimulation. However, the exposure of dentin tubules due to enamel loss by abrasion, erosion, abfraction or root surface exposure caused by gingival recession, periodontal treatment or a combination of both (2) may produce strong dentin sensitivity (3).

Several theorieshavebeen presented tocharacterize dentin hypersensitivity, but the hydrodynamic theory proposed by Brännström is the most widely accepted (4-6). According to its principles, the fluid movement inside the dentin tubules leads to sensorial activation of the nerve cells in the pulp, thus causing pain (7).

It has been reported that 8 to $30 \%$ of adults are affected by dentin hypersensitivity $(8,9)$. Moreover, with more teeth being preserved and retained for longer periods, there will be an increasing demand by patients involved in this uncomfortable situation $(1,10)$. Females have been reported to have a higher incidence of hypersensitivity than males, although the difference is not statistically significant, and the greatest incidence has been documented in the 20 to 40 year-old group (8). The 
most frequently affected teeth are premolars (68.8\%), followed by molars, canines and incisors.

Potassium oxalate is a desensitizing agent that acts not only by obliterating the dentin tubules, with the precipitation of calcium oxalate crystals on the surface and inside the dentin tubules, but also by depolarization of nerve endings. This mechanism explains why desensitizing agents usually act in short- and longterm bases $(11,12)$. Calcium chloride and potassium phosphate solutions have been tested in vitro $(13,14)$ and in vivo (15), and may work similarly. Both approaches have shown very promising results in treating dentin hypersensitivity.

The aim of this study was to evaluate the efficacy of two desensitizing agents in the reduction of dentin hypersensitivity in a randomized, double-blind, splitmouth clinical trial, to test the hypothesis that one of desensitizing agent is better than the other.

\section{MATERIAL AND METHODS}

Caries-free patients who had at least 3 cervical lesions with clinical diagnosis of moderate or severe dentin hypersensitivity, adequate oral hygiene, absence of periodontal disease or parafunctional habits were considered as eligible for this study. The selection of patients was based on clinical and radiographic examinations.

Clinical diagnosis was performed by using an uniform source of light, provided by a conventional operating dental light system, a mouth mirror, an explorer and periodontal probe. With the aid of a film holder (Kodak Ektaspeed plus Film 31r41 mm; Kodak, Rochester, NY, USA), two bitewing radiographs were obtained on each side of the mouth for diagnostic purposes. The teeth selected could not have caries, cracks or fractures, extensive or unsatisfactory restorations, recent restorations involving the buccal surface, prosthesis or orthodontic appliances.

Patient's general health was assessed by an interview. Those who presented severe systemic and/or psychological diseases, constant use of analgesic and/or anti-inflammatory drugs or allergic response to dental products were excluded from the study. The power of paired-sample t-test was calculated to be $80 \%$ for a sample size of 13, the default significance level (alpha level) was set at 0.05 , and the alternative was 2 -sided.

The sample was composed of 77 teeth from 13 healthy patients of both genders ( 2 males and 11 females) with mean age of 30 years who had at least 3 cervical lesions with dentin hypersensitivity and met all other inclusion criteria and did not fall into any of the exclusion criteria mentioned above. Participants were informed about the purpose and design of the investigation and signed an appropriate informed consent form. The research protocol was approved by the Ethics Committee in Research of Medical School of UFC.

The degree of hypersensitivity was determined according to the Verbal Rating Scale - VRS (7) from 0 to 3 , in which: $0=$ no discomfort, $1=$ minimum discomfort, $2=$ mild discomfort, and $3=$ intense discomfort. The values were always collected before and after the application of treatments. Each tooth received two stimuli: clinical probing (tactile stimulus) and air blast (thermalevaporative stimulus). The probe stimulus was applied under slight manual pressure in the mesiodistal direction on the cervical area of the tooth. Air blast was applied with an air syringe for $1 \mathrm{~s}$ at the distance of $1 \mathrm{~cm}$ of the tooth surface to avoid desiccating the dentin surface.

The three treatments were designated to the same patient to permit data correlation regarding his/ her sensitivity threshold. Thus, in each patient, the teeth were randomly divided into 3 different groups according to the desensitizing treatment under study: Oxa-Gel (Kota Import's Ltda., São Paulo, SP, Brazil) (27 teeth) Sensi Kill (DFL Ind. e Com. S.A., Rio de Janeiro, RJ, Brazil) (26 teeth), and placebo gel (Artpele Farmácia com Manipulação Ltda., Fortaleza, CE, Brazil) (24 teeth) (Table 1). This randomization was performed by placing all the selected teeth in a list and assigning its treatment according to a predefined sequence: (a) Oxa-Gel; (b) Sensi Kill; (c) placebo gel. In such way, the tooth presenting the highest number received the first treatment and the tooth with the lowest number received the last one.

The desensitizing agents and placebo were applied by one experienced operator, other than the examiner, as follows: 1) water rinse; dentin prophylaxis to remove gross plaque accumulation; 2) cotton isolation rolls; 3) dentin drying with an air syringe; 4) application of each substance according to the manufacturer's instructions (Table 1); and 5) excess removal by using cotton pellets. The patients were instructed to avoid using any other in-office-desensitizing agent in the course of the investigation.

The efficacy of the products was tested after each session using the VRS to record degree of dentin sensitivity generated. This procedure was repeated at 
7-day intervals for 4 weeks. Scores obtained immediately after 4 applications were considered the immediate results of the treatment. The sensitivity patterns were recorded by an examiner previously calibrated for applying the stimuli. Calibration procedures were carried out using a dental mannequin, air-water syringe, timer and an explorer. Duration of the calibration process (training, and calibration exercises) was approximately $20 \mathrm{~h}$. The order in which the teeth were evaluated within each subject was maintained at each visit. The examiner and the patients did not know which type of treatment corresponded to each tooth. The intra-examiner weighted kappa value was calculated using the baseline values for hypersensitivity, reexamining $20 \%$ of the patients that could be enrolled in the study, and was determined to be 0.87 . Once treatments were concluded, this value was not reassessed because at this time, since at this instance changes in the hypersensitivity scores could be due to treatment and not to intra-examiner's agreement.

In order to verify the performance of the treatments in reducing sensitivity, the numerical scores were analyzed before and after each treatment using a paired $t$ test, considering each stimulus individually. After transformation of data by square root, one-way
ANOVA and Tukey's test were used for comparing the treatments. The significant level was set at 5\%.

\section{RESULTS}

According to paired $\mathrm{t}$ test, all treatments, even the placebo gel, were capable of reducing sensitivity scores for both stimuli (Table 2). According to ANOVA, sensitivity scores were significantly lower $(\mathrm{p}<0.05)$ only for Sensi Kill in comparison to the scores obtained for the other groups (placebo and Oxa-Gel), when air stimulus was applied. Scores before treatment procedures for both stimuli and those obtained after treatments using probe stimulus did not present statistically significant differences ( $p>0.05)$.

\section{DISCUSSION}

This clinical evaluation aimed at comparing the tooth response immediately after application of two commercial desensitizing agents (Oxa-Gel and Sensi Kill), using a placebo gel as a control.

In the present study, all formulations caused significantly reduction on dentin hypersensitivity before

Table 1. Groups, materials and compositions.

\begin{tabular}{|c|c|c|}
\hline Group & Composition & Manufacturer's instructions \\
\hline $\begin{array}{l}\text { Oxa-Gel } \\
(\mathrm{n}=27)\end{array}$ & $\begin{array}{l}\text { 3\% potassium oxalate monohydratate } \\
(\mathrm{pH} 4) \text { solution, carboxymethylcellulose gel }\end{array}$ & $\begin{array}{l}\text { The solution was passively applied on the surface } \\
\text { for } 2 \text { min followed by water rising }\end{array}$ \\
\hline $\begin{array}{l}\text { Sensi Kill } \\
(\mathrm{n}=26)\end{array}$ & $\begin{array}{l}\text { Solution 1: dipotassium phosphate, sodium fluoride, } \\
\text { methylparaben, distilled water; Solution 2: calcium } \\
\text { chloride sodium benzoate and distilled water }\end{array}$ & $\begin{array}{l}\text { The first solution was gently rubbed for } 10 \mathrm{~s} \text { and } \\
\text { kept on the surface for } 30 \mathrm{~s} \text {. The second solution was } \\
\text { rubbed for } 2 \mathrm{~s} \text { and maintained for } 10 \mathrm{~s}\end{array}$ \\
\hline $\begin{array}{l}\text { Placebo } \\
(\mathrm{n}=24)\end{array}$ & carboxymethylcellulose gel, distilled water & $\begin{array}{l}\text { The gel was applied on the surface } \\
\text { for } 2 \text { min followed by water rising }\end{array}$ \\
\hline
\end{tabular}

Table 2. Sensitive scores (mean $\pm \mathrm{SD}$ ) before and after treatments according to the groups and stimuli.

\begin{tabular}{|c|c|c|c|c|c|c|}
\hline \multirow[b]{2}{*}{ Groups } & \multicolumn{3}{|c|}{ Air blast stimulus scores } & \multicolumn{3}{|c|}{ Probing stimulus scores } \\
\hline & Before & After & $\begin{array}{c}\text { p-value } \\
\text { (paired t test) }\end{array}$ & Before & After & $\begin{array}{c}\text { p-value (paired } \\
\text { t test) }\end{array}$ \\
\hline Placebo & $1.7 \pm 0.9^{\mathrm{a}}$ & $1.0 \pm 1.0^{\mathrm{a}}$ & 0.001 & $1.5 \pm 0.8^{\mathrm{a}}$ & $1.0 \pm 1.0^{\mathrm{a}}$ & 0.004 \\
\hline Sensi Kill & $1.5 \pm 1.1^{\mathrm{a}}$ & $0.3 \pm 0.6^{\mathrm{b}}$ & $<0.001$ & $1.1 \pm 0.9^{\mathrm{a}}$ & $0.4 \pm 0.6^{\mathrm{a}}$ & $<0.001$ \\
\hline Oxa-Gel & $1.8 \pm 1.1^{\mathrm{a}}$ & $1.0 \pm 0.9^{\mathrm{a}}$ & 0.001 & $1.5 \pm 1.0^{\mathrm{a}}$ & $0.7 \pm 1.0^{\mathrm{a}}$ & 0.003 \\
\hline
\end{tabular}

$\mathrm{p}$-values obtained with paired t test $(\mathrm{p}<0.05)$; Lowercase superscript letters compare treatments by columns. 
the conclusion of the treatment, in the second and third applications. Five teeth did not present any painful symptomatology after the second application and other four teeth after the third application.

The main component in the Oxa-Gel formulation is monopotassium-monohydrogen oxalate. This agent acts by precipitation of calcium oxalate crystals in the dentin tubules. Greenhill and Pashley (17) reported that $30 \%$ potassium oxalate reduced dentin permeability by $98 \%$ in vitro. Another study (12) found that various potassium oxalate formulations decreased dentin permeability by approximately $75 \%$, indicating the effectiveness of these products. Laboratory tests of desensitizing agents are conducted to evaluate their effectiveness or to predict their clinical performance. Laboratory studies, however, do not reflect the clinical behavior of the material or technique, and clinical evaluations are mandatory to confirm the efficiency of product $(2,7,16)$.

Pashley et al. (18) concluded that the formation of calcium oxalate crystals occurs $30 \mathrm{~s}$ after the application of oxalate-based solutions, thus decreasing dentin permeability. These authors also observed that such solutions were proven even more effective when applied for $60 \mathrm{~s}$. In the present study, the desensitizing agents were applied for $2 \mathrm{~min}$ as instructed by Oxa-Gel's manufacturer, a sufficient time for crystal precipitation.

According to its manufacturer, Sensi Kill acts occluding the dentin tubules by the deposition of calcium phosphate. The mineralized substances are deposited in and over the dentin tubules, resulting in a quick precipitation of amorphous calcium phosphate, which is rapidly converted into apatite.

In spite of having similar mechanisms of action on teeth, Sensi Kill and Oxa-Gel promoted different results on the reduction of hypersensitivity to air blast stimulus. This is probably because although the two agents act mainly by obliteration of dentin tubules, the Sensi Kill's precipitates are likely to be more stable because amorphous calcium phosphate crystals are found in the tooth surface and are transformed into apatite. The calcium oxalate crystals formed after application of Oxa-Gel may be more unstable, promoting a less effective obliteration.

Placebo control is defined as a formulation containing no ingredients expected to have or proven to be of therapeutic value in dentin hypersensitivity (19). Although the placebo formulation consists of inert substances, the hypothesis of a mechanical tubule occlusion by the carboxymethylcellulose particles cannot be discarded (7). Moreover, a positive dentist/patient relationship can reduce patient anxiety and improve his/her motivation to obtain relief $(7,20)$. The positive results achieved in the placebo group suggest the need of further clinical studies for better understanding such intriguing event and for establishing clinical protocols for the study of dentin hypersensitivity.

Several treatment modalities and agents have been used in the management and resolution of dentin hypersensitivity, but their efficacy has varied from one study to another and it is not yet established in the literature $(2,15,20-23)$. Further research is needed to clarify the mechanisms and etiology of this uncomfortable clinical condition.

The present study suggests that knowledge of the commercially available desensitizing products and the factors involved in the mechanisms of dentin hypersensitivity is mandatory to undertake an effective treatment. There was efficacy in dentin hypersensitivity reduction with all treatments, with better performance of Sensi Kill after exposure to air blast stimulus. Placebo treatment reduced the degree of hypersensitivity, suggesting that its effect plays an important role in this scenario and should be further investigated.

\section{RESUMO}

O objetivo desse estudo foi avaliar a eficiência de dois agentes dessensibilizantes na redução da hipersensibilidade dentinária, em um estudo clínico aleatório do tipo boca-dividida e duplocego. Setenta e sete dentes de 13 pacientes que apresentavam algum grau de sensibilidade à sondagem e/ou estímulo ao ar foram tratados com um dos seguintes agentes dessensibilizantes: Oxa-Gel (G1), Sensi Kill (G2) e gel placebo (G3-controle). De acordo com o teste $t$ pareado, todos os tratamentos, inclusive o placebo, foram capazes de reduzir os escores para ambos os estímulos. A análise dos dados pelos testes de ANOVA e de Tukey $(\alpha=0,05)$ demonstrou que os escores de sensibilidade foram significantemente menores somente para o Sensi-Kill em comparação aos outros produtos (Oxa-Gel e placebo) quando o estímulo ar foi aplicado. Pode-se concluir que o tratamento com Sensi-Kill apresentou um desempenho ligeiramente melhor na redução da hipersensibilidade dentinária quando comparados aos outros agentes dessensibilizantes.

\section{REFERENCES}

1. Orchardson R, Gangarosa LP, Holland GR, Pashley DH, Trowbridge HO, Ashley FP, et al.. Dentine hypersensitivity-Into the 21st century. Arch Oral Biol 1994;39:113S-119S.

2. Olusile AO, Bamise CT, Oginni AO, Dosumu OO. Short-term clinical evaluation of four desensitizing agents. J Contemp Dent Pract 2008;9:22-29. 
3. Ladalardo TC, Pinheiro A, Campos RA, Brugnera Júnior A, Zanin F, Albernaz PL, et al.. Laser Therapy in the treatment of dentine hypersensitivity. Braz Dent J 2004;15:144-150.

4. Brännström M. Sensitivity of dentin. Oral Surg 1966;21:517-526.

5. Chidchuangchai W, Vongsavan N, Matthews B. Sensory transduction mechanisms responsible for pain caused by cold stimulation of dentine in man. Arch Oral Biol 2007;52:154-160.

6. Walters PA. Dentinal hypersensitivity: a review. J Contemporary Dent Practice 2005;6:1-10.

7. Pereira JC, Martineli ACBF, Santiago SL. Treating hypersensitive dentin with three different potassium oxalate-based gel formulations: a clinical study. J Appl Oral Sci 2001;9:123-130.

8. Fischer C, Fischer RG, Wennberg A. Prevalence and distribution of cervical dentine hypersensitivity in a population in Rio de Janeiro, Brazil. J Dent 1992;20:272-276.

9. Rees JS, Addy M. A cross-sectional study of dentine hypersensitivity. J Clin Periodontol 2002;29:997-1003.

10. Bissada NF. Symptomatology and clinical features of hypersensitive teeth. Arch Oral Biol 1994;39:31-32.

11. Pashley DH. Dentin permeability, dentin sensitivity, and treatment through tubule occlusion. J Endod 1985;12:465-474.

12. Santiago SL, Pereira JC, Martineli AC. Effect of commercially available and experimental potassium oxalate-based dentin desensitizing agents in dentin permeability: influence of time and filtration system. Braz Dent J 2006;17:300-305.

13. Pereira JC, Martineli AC, Tung MS. Replica of human dentin treated with different desensitizing agents: a methodological SEM study in vitro. Braz Dent J 2002;13:75-85.

14. Suge T, Ishikawa K, Kawasaki A, Yoshiyama M, Asaoka K, Ebisu S. Effects of fluoride on the calcium phosphate precipitation method for dentinal tubule occlusion. J Dent Res 1995;74:10791085 .
15. Yeates R, Owens R, Jackson R, Newcombe RG, Addy M. A splitmouth placebo-controlled study to determine the effect of amorphous calcium phosphate in the treatment of dentin hypersensitivity. J Clin Periodontol 1998;25:687-692.

16. Vieira AHM, Passos VF, Assis JS, Mendonça JS, Santiago SL. Clinical evaluation of a $3 \%$ potassium oxalate gel and a GaAIAs laser for the treatment of dentinal hypersensitivity. Photomed Laser Surg 2009;27:807-812.

17. Greenhill JD, Pashley DH. The effects of desensitizing agents on the hydraulic conductance of human dentin in vitro. J Dent Res 1981;60:686-698.

18. Pashley DH, O'Meara JA, Kepler EE, Galloway SE, Thompson SM, Stewart FP. Dentin permeability. Effects of desensitizing dentifrice in vitro. J Periodontol 1984;55:522-525.

19. Holland GR, Narhi MN, Addy M, Gangarosa L, Orchardson R. Guidelines for the design and conduct of clinical trials on dentine hypersensitivity. J Clin Periodontol 1997;24:808-813.

20. Vieira AHM, Santiago SL. Management of dentinal hypersensitivity. Gen Dent 2009;57:120-126.

21. Sharma N, Roy S, Kakar A, Greenspan DC, Scott R. A clinical study comparing oral formulations containing $7.5 \%$ calcium sodium phosphosilicate (NovaMin), $5 \%$ potassium nitrate, and $0.4 \%$ stannous fluoride for the management of dentin hypersensitivity. J Clin Dent 2010;21:88-92.

22. Salian S, Thakur S, Kulkarni S, LaTorre G. A randomized controlled clinical study evaluating the efficacy of two desensitizing dentifrices. J Clin Dent 2010;2:82-87.

23. Tirapelli C, Panzeri H, Soares RG, Peitl O, Zanotto ED. A novel bioactive glass-ceramic for treating dentin hypersensitivity. Braz Oral Res 2010;24:381-387. 